\title{
High Plasma Concentrations of Sclerostin, an Inhibitor of the Wnt Signaling Pathway, in Young Horses Affected by Osteochondrosis
}

\author{
Didier Serteyn 1,2,3, Luis Mendoza1,2, Charlotte Sandersen ${ }^{1,3}$, Isabelle Caudron ${ }^{1,2}$, \\ David Piquemal ${ }^{4,5}$, Pascale Chavatte-Palmer6, Jean-Philippe Lejeune ${ }^{2,3}$ \\ ${ }^{1}$ Equine Clinic, University of Liege, Liege, Belgium \\ ${ }^{2}$ Equine Research and Development Center, Mont-le-Soie, Belgium \\ ${ }^{3}$ Center of Oxygen, Research and Development, University of Liege, Liege, Belgium \\ ${ }^{4}$ Computational Biology Institut (IBC), Montpellier, France \\ ${ }^{5}$ Acobiom, Montpellier, France \\ ${ }^{6}$ INRA, URM1198 Biologie du Développement et Reproduction, F-78350 Jouy en Josas, Paris, France \\ Email: Didier.serteyn@ulg.ac.be
}

Received 30 September 2014; revised 16 November 2014; accepted 29 November 2014

Academic Editor: Andreas Roth, Universität Leipzig, Germany

Copyright (C) 2014 by authors and Scientific Research Publishing Inc.

This work is licensed under the Creative Commons Attribution International License (CC BY).

http://creativecommons.org/licenses/by/4.0/

(c) (i) Open Access

\section{Abstract}

Osteochondrosis (OC) is a developmental disease in horses with a significant impact on the horse's welfare and performance. The early disturbance of enchondral ossification progresses to inflammatory and healing process in older horses. Metabolic pathway analysis showed an obvious dysregulation of several signaling pathways related to cartilage formation and cartilage repair such as Wnt/ $\beta$-catenin, Indian hedgehog and TGF- $\beta$ signaling pathways. Other regulated genes appeared to be involved in high carbohydrate diet, abnormal insulin metabolism or inflammation. Sclerostin is an osteocyte-secreted soluble antagonist of the Wnt/ $\beta$-catenin signaling pathway. It is crucial for osteoblast development and activity and is increased in naturally occurring lesions of equine osteochondrosis. The aim of this study is to compare the circulating sclerostin levels between OC-affected $(n=20)$ and healthy horses $(n=19)$. A significant linear regression between plasma sclerostin and age is observed especially in the healthy young horses. The mean plasma sclerostin concentration is significantly higher in young horses suffering from osteochondrosis compared to the control horses. These results reinforce the possible role of the $\mathrm{Wnt} / \boldsymbol{\beta}$-catenin signaling pathway in the OC pathogeny. The inhibition of this essential pathway could disturb the osteo-chondral differentiation. More studies are currently needed to define the eventual clinic interest of plasma sclerostin as future biomarker in bone and cartilage diseases. 


\section{Keywords}

\section{Sclerostin, Osteochondrosis, Wnt/ $\beta$-Catenin Pathway, Horse, Equine Osteochondrosis}

\section{Introduction}

Osteochondrosis (OC) is a developmental disease of growing horses. It is defined as a disturbance in the process of endochondral ossification [1] which can lead to the formation of detached fragments (osteochondrosis dissecans (OCD)), fissures, or subchondral bone cysts at the epiphyseal growth cartilage [1] [2]. OCD is a frequent cause of pain, lameness and reduced performance in young athletic horses [3] [4]. The disease appears to be multifactorial in origin, including skeletal growth rates, nutrition, endocrinological factors, exercise, biomechanics, and genetic effects [5].

In a previous study, we analyzed the transcript profile of leukocytes from horses affected with OC using the high throughput sequencing method digital gene expression analysis [6]. Metabolic pathway analysis showed an obvious deregulation of several signaling pathways related to cartilage formation and cartilage repair such as Wnt $/ \beta$-catenin, Indian hedgehog- and TGF- $\beta$ signaling pathways. Other regulated genes may play a role in high carbohydrate diet, abnormal insulin metabolism or inflammation [6]. Power and others [7] demonstrated that sclerostin protein was increased in naturally occurring lesions of equine osteochondrosis.

Sclerostin is a small protein specifically expressed by osteocytes which antagonizes canonical Wnt $\beta$-catenin signaling by binding to Wnt co-receptors, low-density lipoprotein receptor-related protein 4, 5 and 6 [8] (Figure 1). Sclerostin coded by the SOST gene in osteocytes. Sclerostin is mainly produced in respond to mechanical stress applied to the skeleton. It appears to play an important role in the regulation of bone remodeling [9]. Recent studies have shown that the SOST gene is also expressed by articular chondrocytes and that modulation of its activity may have effects on articular cartilage and subchondral bone [10].

In humans, serum sclerostin levels are gender dependent and increase with age as well as in several pathologies such as diabetes, obesity and osteoporosis [11]-[13]. In cases of juvenile idiopathic arthritis (JIA), soluble antagonists of the canonical Wnt/ $\beta$-catenin signaling were measured in serum and subsequently induced inhibition of osteoblast proliferation, maturation, and progenitor differentiation. A significant correlation between the sclerostin serum concentration and the number of tender and swollen joints supports the hypothesis that chondrocytes and cells of the subchondral bone may contribute to circulating sclerostin in JIA [14].

The aim of the present study is to demonstrate the implication of the Wnt/ $\beta$-catenin signaling pathway by measuring in young horses suffering from osteochondrosis, the concentration of circulating sclerostin and to compare these values to a group of healthy horses without any suspect radiologic signs of osteochondrosis.

\section{Materials \& Methods}

\subsection{Population}

Thirty-nine young Belgian Warm blood horses, with a mean age of $268( \pm 63.55)$ days, were selected for this study which followed a "case control study" model. Selection was made between 125 examined horses in 2014 on the base of the uncountable results of the radiographies. The foals were presented at the European Center of the horse (Vielsalm, Belgium) by the breeders in the context of the orthopedic diseases screening program promoted by the Wallonia Region. All the foals were weaned and fed a diet based on hay or haylage and concentrates. The OC affected group was composed of 6 females and 14 males. The control group was composed of 9 females and 10 males. Although veterinary examinations were performed routinely, the ethics committee of the University of Liege has agreed to the study protocol.

\subsection{Radiographic Exam}

All horses were sedated for the radiographic examination using detomidine $(0.01 \mathrm{mg} / \mathrm{kg} \mathrm{IV})$ alone or combined with butorphanol $(0.02 \mathrm{mg} / \mathrm{kg}$ IV). The following views were taken: lateromedial views of the 4 fetlocks, lateromedial and plantarolateral-dorsomedial oblique views of the hocks and a lateromedial view of the stifles. Extra views were taken when necessary. Horses were diagnosed on the basis of characteristic lesions of abnormal endochondral ossification located in the metacarpo and metarso-phalangeal, tibiotarsal, and femoro-patellar joints [15]. The foals presenting one lesion in the fetlock joint such as fragmentation and irregularity observed 
on the dorsal aspect of the sagittal ridge and the condyles of the metacarpus or metatarsus or dorsal, palmar or plantar fragmentations at the margin of the proximal phalanx were not included in this study. Concerning the stifle joint, variably sized irregularity or flattening of the lateral trochlear ridge of the femur with sometimes partial calcification of the tissue within the defect were considered as OC-lesions (Figure 2(a)). Concerning the hock, OC-lesions were identified as fragments still in place (intermediate ridge) (Figure 2(b)) or surface irregularities of the trochlear ridge(s) or malleolus. Horses with osteoarthrosis and other radiological abnormalities were also excluded of this study.

The OC-affected group included 20 horses and 19 horses without any evidence of OC lesions were analyzed as control groups. At the moment of the radiographic exams, blood samples were collected from each horse on EDTA or dry tubes. Plasma and serum were frozen at $-20^{\circ} \mathrm{C}$ for later analysis.

\subsection{Sclerostin Assay}

Serum sclerostin concentrations were determined by a sandwich ELISA kit designed and validated specifically

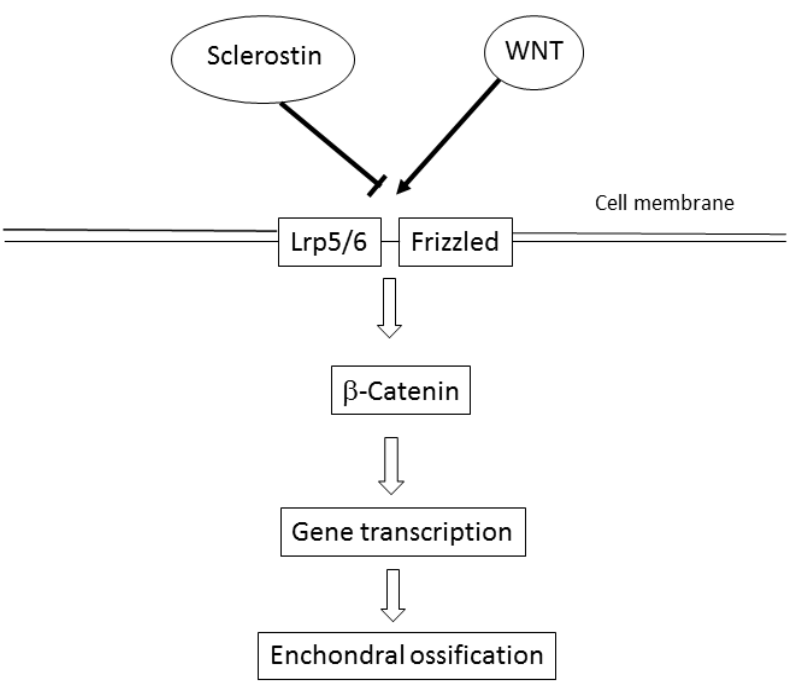

Figure 1. Modulation of the Wnt B-catenin pathway by sclerostin (modified from M. Lewiecki, 2011, discovery medicine) The binding of Wnt proteins to the LRP5/6-Frizzled co-receptor on the cell membrane leads to stabilization of intracellular $\beta$-catenin and regulation of gene transcription that promotes ossification. Sclerostin by binding to LRP5/6 antagonizes Wnt signaling and inhibits enchondral ossification.

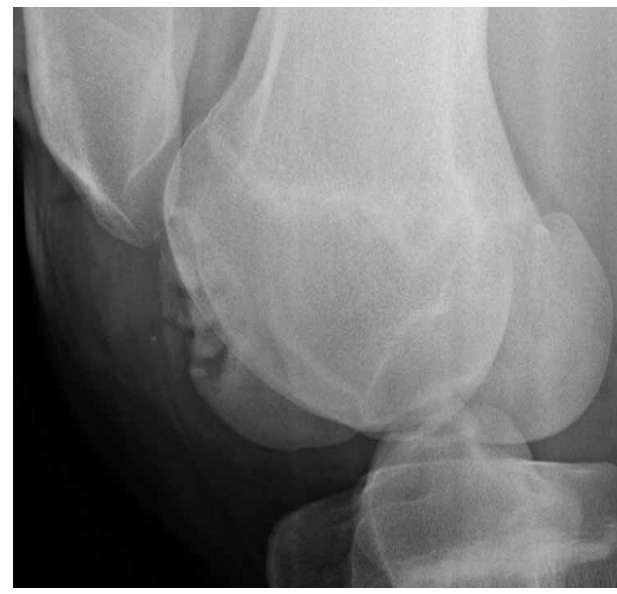

(a)

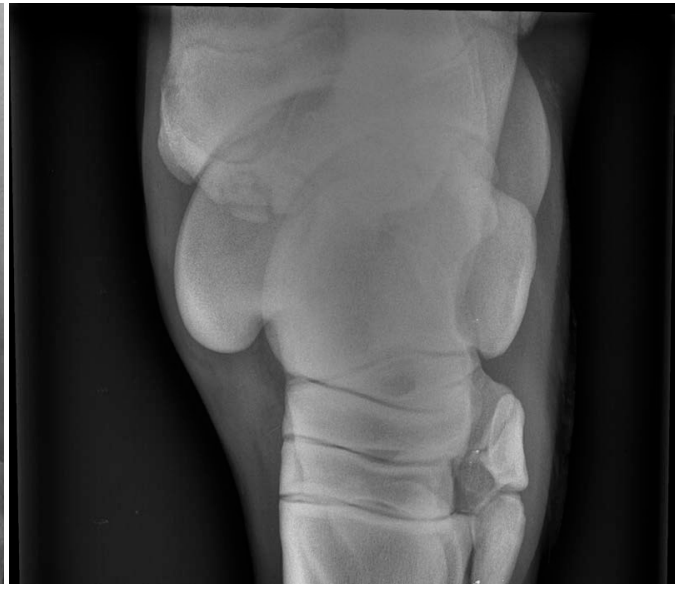

(b)

Figure 2. OC lesion in the lateral ridge of the femoral trochlea (a) and OC lesion of the intermediate ridge of the tibial trochleaas examples of the lesions found during the radiographic exams (b). 
for equine samples (Horse Sclerostin (SOST) ELISA Kit, MyBioSource, BiopTis). Sclerostin standards ranging from 31.2 to $1000 \mathrm{pg} / \mathrm{ml}$ andundiluted serum were added $(50 \mu \mathrm{l})$ into the wells of a microplate then $100 \mu \mathrm{l}$ of HRP-conjugate reagent was added to each well. The microplate was incubated for 60 minutes at $37^{\circ} \mathrm{C}$. After incubation, the microplate was washed 4 times with the wash solution of the kit and $100 \mu$ l of the TMB-peroxidase substrate (mix of chromogen solutions A and B) was added to reveal the peroxidase activity of the HRP conjugate. The plate was incubated for 15 minutes at $37^{\circ} \mathrm{C}$ then $50 \mu \mathrm{l}$ of the acidic stop solution was added. The absorbance of the yellow color was read at $450 \mathrm{~nm}$ with the Multiscan Ascent plate reader. Each sample was assayed twice and the mean value was calculated. According to the firm, the sensitivity of the kit is $5.0 \mathrm{pg} / \mathrm{ml}$.

\subsection{Statistical Analysis}

Equality of variances was assessed by Levene's test. Linear regressions were calculated between the values of sclerostin and age in all horses and then in each group. A global linear model was used to compare the mean values of plasma concentrations of sclerostin (variable) between the OC-affected group and the control group (factor A) taking into account the sex (factor B) and the age (covariate). Significance was set at $\mathrm{P} \leq 0.05$. Medcalc software, Ostend, Belgium.

\section{Results}

The Levene's test was not significant assuming the equality of variances. A significant linear relation existed between the plasma sclerostin values and the age $\left(\mathrm{R}^{2}=0.12 ; \mathrm{P}=0.03\right)$. Figure 3 illustrates the results of the linear regression calculation for the two groups: the OC-affected horses and the control group. A significant linear relationship was observed only in the control group $\left(R^{2}=0.28 ; P=0.01\right)$.

The global linear model showed a significant effect of the OC-status $(\mathrm{P}=0.035)$ and a non-significant effect of the sex $(\mathrm{P}=0.75)$. Mean values of sclerostin $( \pm \mathrm{SE})$ in the OC-affected horses were $71.6 \pm 3.3 \mathrm{pmole} / \mathrm{L}$ and $61.5+/-3.2$ pmole/l in the control horses. Figure 4 illustrates the box and wisker plot.

\section{Discussion}

To our knowledge, this is the first time that the circulating levels of sclerostin are measured in horses. A recent study shows that sclerostin in humans varies according to sex and age [16] and that sclerostin levels were higher in men than in women independently of their age. This was explained by the higher bone mass that men usually have. Sclerostin is mainly expressed by osteocytes, so individuals with higher bone mass, consequently, have a

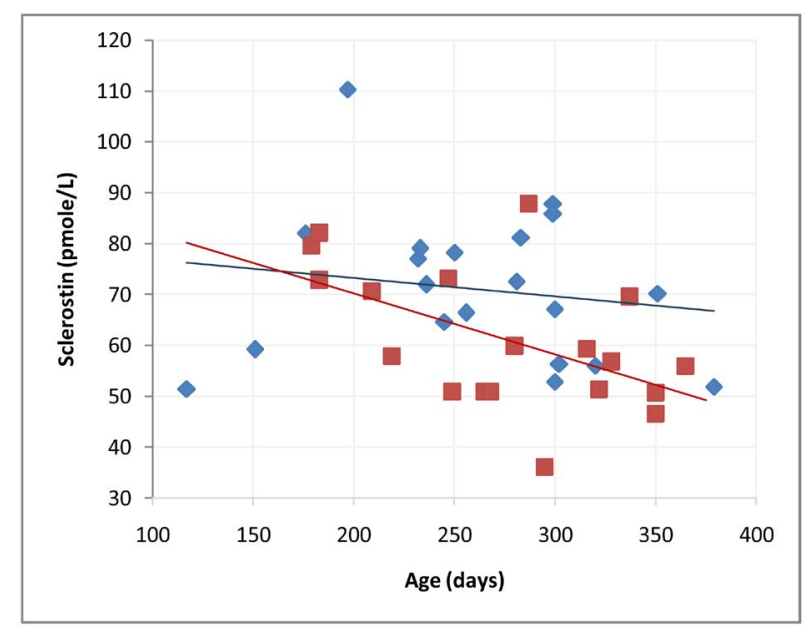

Figure 3. Linear relationship between of sclerostin levels in the OC (blue) and in the control group (red) related to the age. Both groups together show a significant $(P=0.03)$ decrease in the sclerostin concentration with age. When considered separately, the linear relation is only significant in the healthy group $(\mathrm{P}=$ $0.01)$. 


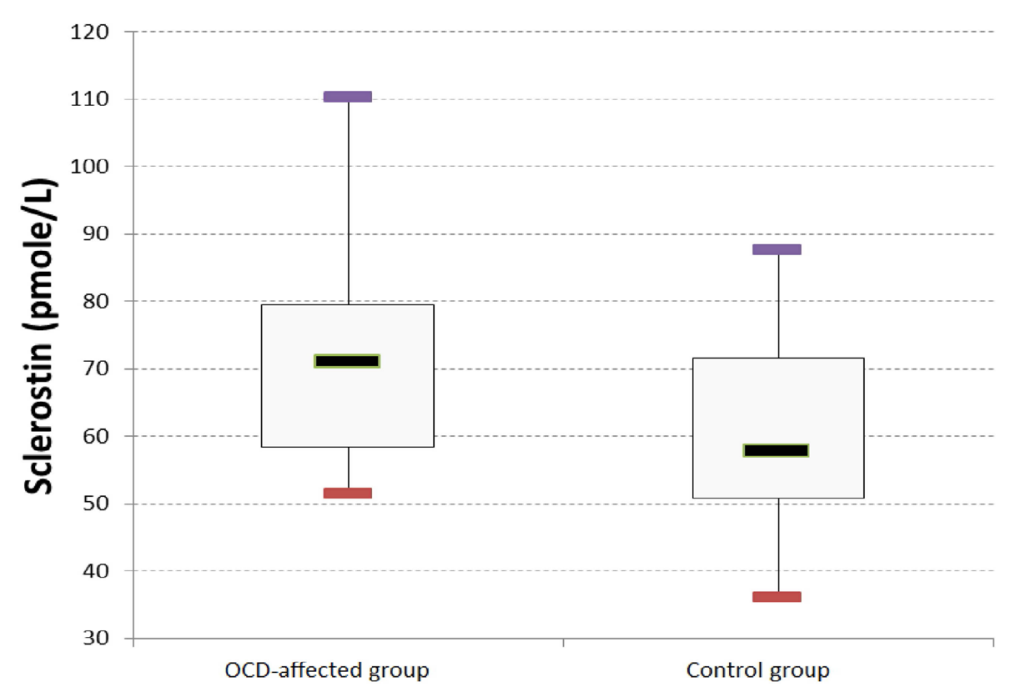

Figure 4. Box and Wisker plot comparing the OC and the control group. The OC affected group has a significant $(\mathrm{P}=0.035)$ higher concentration of sclerostin than the control group.

higher number of osteocytes. Sclerostin levels in humans are rising with age, but studies concerned people aged from 20 to approximately 60 years. In our study we found that sclerostin levels are decreasing with the age but our study included only young horses during their growth. The adult human normal values of sclerostin in serum were between 10 and 40 pmole/L [16]. Until now, there were no reference values in horses. Our control group (not affected by osteochondrosis) had a mean value of 61.5 pmole/L. The affected group had a mean value of $71.6 \mathrm{pmole} / \mathrm{L}$ in serum. For this reason, we have chosen to perform a case control study and two groups of young horses of the same age were selected. The horses of the control group did not show any signs of OC in the fetlocks, hocks and stifles. For the OC-affected horses we have chosen only cases with radiological lesions associated that were undoubtedly osteochondrosis in the hocks or the stifles. Indeed, some lesions in the fetlocks are not clearly associated with osteochondrosis such as the first phalanx dorsal or plantar fragments [17]. Furthermore, all the horses were weaned and examined during the winter period in order to minimize the environmental effects. A study performed in 2014 shows that sclerostin levels are influenced by season in human [18]. In winter season, sclerostin concentration is $20 \%$ higher than the all-year mean.

Several limitations of our study came from the fact that we did not know the exact composition of the diet, the housing conditions, the body condition scores and intensity of daily exercise. All these factors may influence the expression of the disease [19]-[21].

Based on a digital gene expression analysis, our group analyzed the transcript profile of leukocytes from horses affected with OC using the high throughput sequencing method digital gene expression analysis [6]. Metabolic pathway analysis showed an obvious dysregulation of several signaling pathways related to cartilage formation and cartilage repair such as Wnt $\beta$-catenin, Indian hedgehog- and TGF- $\beta$ signaling pathways. Other genes regulated may play a role in high carbohydrate diet, abnormal insulin metabolism or inflammation [6]. Furthermore, the transcript profile of leukocytes demonstrated that OC-related genes are differentially expressed in horses of different ages when compared to their age-matched controls and are differently expressed according the affect joints in young foals ( $<12$ months) [22] [23]. Recently a miRNAs profile study in cartilage samples showed that miRNAs might be involved in equine OC physiopathology and in the cellular response to the biomechanical stress in cartilage and bone [24].

$\mathrm{Wnt} / \beta$-catenin signaling pathway is a major regulator of the bone activity [25]. The activation of this pathway leads to the formation and differentiation of osteoblastic cells, which create and increase the bone mass. This pathway starts when the appropriate Wnt peptide binds to the receptors LRP4, 5 and 6 (lipoprotein receptor related-protein) [26]. Sclerostin is an antagonist peptide of $\mathrm{Wnt} / \beta$-catenin pathway that binds to these receptors acting as a negative regulator of the bone formation.

Concerning the possible implication of Wnt $/ \beta$-catenin pathway in the osteochondrosis, Power and others [7] demonstrated that sclerostin was increased in naturally occurring lesions of growth cartilage. They concluded 
that given that sclerostin protein is increased in lesions of OC, and that OC is associated with retained cartilage, it is possible that sclerostin may be having an effect on the cartilage via protease action, as proposed in OA. In that study samples were taken from stifle cartilage. In our study, the sclerostin concentrations were measured in peripheral blood.

Besides the effects on bone metabolism and the growing awareness of the role of sclerostin in human osteoporosis, the Wnt/ $\beta$-catenin pathway and sclerostin are also involved in certain inflammatory and metabolic diseases such as obesity and diabetes [27] [28]. For example, humans suffering from type 2 diabetes have higher sclerostin levels that the controls [27].

Several omics studies underlined also the role of an energetic metabolism dysfunction in the osteochondrosis development. Desjardin and others [29] observed abnormal mitochondria and endoplasmic reticulum in the deep zone of OC cartilage. The mitochondrial dysfunction could be partially explained by the altered Wnt/ $\beta$-catenin signaling pathway also known as a key regulator of mitochondrial function [6] [7] [30].

Sclerostin is expressed by the SOST gene and a modulation of sclerostin levels appears to be a finely tuned mechanism by which osteoblast, chondrocytes and progenitor cells coordinate regional and local osteogenesis [31]. Methylation of bone SOST, its mRNA, and serum sclerostin levels correlate strongly with fracture risk in postmenopausal women [32]. Delgado-Calle and others [33] showed that the SOST is subject to an epigenetic regulation. In that study osteoblasts were hypermethylated and osteocytes were hypomethylated in a CpG-rich region in the SOST proximal promoter.

\section{Conclusion}

To conclude, based on the recent studies in equine and human medicine, we can support the concept that genetic and epigenetic changes in SOST gene influence its bone mRNA expression and serum sclerostin levels in osteochondrosis. These results reinforce the possible role of the $\mathrm{Wnt} / \beta$-catenin signaling pathway in the OC pathogeny. However, as in human medicine, more studies are needed to define an eventual clinic interest of plasma sclerostin as future biomarker in bone and cartilage diseases.

\section{Acknowledgements}

We thank the Wallonia Region for their funding providing. We also thank B. Deliege, A. Niesten and P. Lejeune for their excellent technical assistance.

\section{References}

[1] Rejno, S. and Stromberg, B. (1978) Osteochondrosis in the Horse. II. Pathology. Acta Radiologica-Supplement, 358, 153-178.

[2] Ytrehus, B., Carlson, C.S. and Ekman, S. (2007) Etiology and Pathogenesis of Osteochondrosis. Veterinary Pathology, 44, 429-448. http://dx.doi.org/10.1354/vp.44-4-429

[3] Verwilghen, D.R., Janssens, S., Busoni, V., Pille, F., Johnston, C. and Serteyn, D. (2013) Do Developmental Orthopaedic Disorders Influence Future Jumping Performances in Warmblood Stallions? Equine Veterinary Journal, 45, 578-581. http://dx.doi.org/10.1111/evj.12027

[4] McIlwraith, C.W. (1993) Inferences from Referred Clinical Cases of Osteochondritis Dissecans. Equine Veterinary Journal, 25, 27-30. http://dx.doi.org/10.1111/j.2042-3306.1993.tb04850.x

[5] Jeffcott, L.B. (1991) Osteochondrosis in the Horse-Searching for the Key to Pathogenesis. Equine Veterinary Journal, 23, 331-338. http://dx.doi.org/10.1111/j.2042-3306.1991.tb03733.x

[6] Serteyn, D., Piquemal, D., Vanderheyden, L., Lejeune, J.P., Verwilghen, D. and Sandersen, C. (2010) Gene Expression Profiling from Leukocytes of Horses Affected by Osteochondrosis. Journal of Orthopaedic Research, 28, 965-970.

[7] Power, J., Hernandez, P., Wardale, J. and Henson, F.M.D. (2014) Alterations in Sclerostin Protein in Lesions of Equine Osteochondrosis. Veterinary Record Open, 1, e000005-e000005. http://dx.doi.org/10.1136/vropen-2013-000005

[8] ten Dijke, P., Krause, C., de Gorter, D.J., Lowik, C.W. and van Bezooijen, R.L. (2008) Osteocyte-Derived Sclerostin Inhibits Bone Formation: Its Role in Bone Morphogenetic Protein and Wnt Signaling. Journal of Bone and Joint Surgery, 90(S1), 31-35. http://dx.doi.org/10.2106/JBJS.G.01183

[9] Moester, M.J., Papapoulos, S.E., Lowik, C.W. and van Bezooijen, R.L. (2010) Sclerostin: Current Knowledge and Future Perspectives. Calcified Tissue International, 87, 99-107. http://dx.doi.org/10.1007/s00223-010-9372-1

[10] Chan, B.Y., Fuller, E.S., Russell, A.K., Smith, S.M., Smith, M.M., Jackson, M.T., Cake, M.A., Read, R.A., Bateman, 
J.F., Sambrook, P.N. and Little, C.B. (2011) Increased Chondrocyte Sclerostin May Protect against Cartilage Degradation in Osteoarthritis. Osteoarthritis and Cartilage, 19, 874-885. http://dx.doi.org/10.1016/j.joca.2011.04.014

[11] Gaudio, A., Privitera, F., Battaglia, K., Torrisi, V., Sidoti, M.H., Pulvirenti, I., Canzonieri, E., Tringali, G. and Fiore, C.E. (2012) Sclerostin Levels Associated with Inhibition of the Wnt/Beta-Catenin Signaling and Reduced Bone Turnover in Type 2 Diabetes Mellitus. Journal of Clinical Endocrinology \& Metabolism, 97, 3744-3750. http://dx.doi.org/10.1210/jc.2012-1901

[12] Appelman-Dijkstra, N.M. and Papapoulos, S.E. (2014) Novel Approaches to the Treatment of Osteoporosis. Best Practice \& Research Clinical Endocrinology \& Metabolism, 28, 843-857. http://dx.doi.org/10.1016/j.beem.2014.07.003

[13] Zhang, H., He, J.W., Wang, C., Zhang, Z., Yue, H., Hu, W.W., Gu, J.M., Hu, Y.Q., Li, M., Fu, W.Z. and Zhang, Z.L. (2014) Associations of Polymorphisms in the SOST Gene and Bone Mineral Density in Postmenopausal Chinese Women. Osteoporosis International, 25, 2797-2803. http://dx.doi.org/10.1007/s00198-014-2832-0

[14] Brabnikova-Maresova, K., Jarosova, K., Pavelka, K. and Stepan, J.J. (2014) Serum Sclerostin in Adult High-Activity Patients with Juvenile Idiopathic Arthritis. Arthritis Research \& Therapy, 16, 460. http://dx.doi.org/10.1186/s13075-014-0460-x

[15] Denoix, J.M., Jacquet, S., Lepeule, J., Crevier-Denoix, N., Valette, J.P. and Robert, C. (2013) Radiographic Findings of Juvenile Osteochondral Conditions Detected in 392 Foals Using a Field Radiographic Protocol. The Veterinary Journal, 197, 44-51. http://dx.doi.org/10.1016/j.tvjl.2013.03.040

[16] Modder, U.I., Hoey, K.A., Amin, S., McCready, L.K., Achenbach, S.J., Riggs, B.L., Melton 3rd, L.J. and Khosla, S. (2011) Relation of Age, Gender, and Bone Mass to Circulating Sclerostin Levels in Women and Men. Journal of Bone and Mineral Research, 26, 373-379. http://dx.doi.org/10.1002/jbmr.217

[17] Hilla, D. and Distl, O. (2014) Heritabilities and Genetic Correlations between Fetlock, Hock and Stifle Osteochondrosis and Fetlock Osteochondral Fragments in Hanoverian Warmblood Horses. Journal of Animal Breeding and Genetics, 131, 71-81. http://dx.doi.org/10.1111/jbg.12062

[18] Dawson-Hughes, B., Harris, S.S., Ceglia, L. and Palermo, N.J. (2014) Serum Sclerostin Levels Vary with Season. Journal of Clinical Endocrinology \& Metabolism, 99, E149-E152. http://dx.doi.org/10.1210/jc.2013-3148

[19] Vander Heyden, L., Lejeune, J.P., Caudron, I., Detilleux, J., Sandersen, C., Chavatte, P., Paris, J., Deliege, B. and Serteyn, D. (2013) Association of Breeding Conditions with Prevalence of Osteochondrosis in Foals. Veterinary Record, 172, 68. http://dx.doi.org/10.1136/vr.101034

[20] Robert, C., Valette, J.P., Jacquet, S., Lepeule, J. and Denoix, J.M. (2013) Study Design for the Investigation of Likely Aetiological Factors of Juvenile Osteochondral Conditions (JOCC) in Foals and Yearlings. The Veterinary Journal, 197, 36-43. http://dx.doi.org/10.1016/j.tvjl.2013.03.039

[21] Lepeule, J., Bareille, N., Robert, C., Valette, J.P., Jacquet, S., Blanchard, G., Denoix, J.M. and Seegers, H. (2013) Association of Growth, Feeding Practices and Exercise Conditions with the Severity of the Osteoarticular Status of Limbs in French Foals. The Veterinary Journal, 197, 65-71. http://dx.doi.org/10.1016/j.tvjl.2013.03.043

[22] Serteyn, D., Piquemal, D., Mendoza, L., Caudron, I., Noguier, F., Bruno, R., Sandersen, C. and Lejeune, J.P. (2014) Osteochondrosis-Related Gene Expression in Equine Leukocytes Differs among Affected Joints in Foals. Journal of Molecular Biomarkers \& Diagnosis, 5, 189. http://dx.doi.org/10.4172/2155-9929.1000189

[23] Mendoza, L., Piquemal, D., Lejeune, J.P., Vander Heyden, L., Noguier, F., Bruno, R., Sandersen, C. and Serteyn, D. (2014) Age-Dependent Expression of Osteochondrosis-Related Genes in Equine Leukocytes. Veterinary Record, Unpublished.

[24] Desjardin, C., Vaiman, A., Mata, X., Legendre, R., Laubier, J., Kennedy, S.P., Laloe, D., Barrey, E., Jacques, C., Cribiu, E.P. and Schibler, L. (2014) Next-Generation Sequencing Identifies Equine Cartilage and Subchondral Bone miRNAs and Suggests Their Involvement in Osteochondrosis Physiopathology. BMC Genomics, 15, 798. http://dx.doi.org/10.1186/1471-2164-15-798

[25] Xu, H., Duan, J., Ning, D., Li, J., Liu, R., Yang, R., Jiang, J.X. and Shang, P. (2014) The Role of Wnt Signaling in Fracture Healing. BMB Reports.

[26] Baron, R. and Rawadi, G. (2007) Targeting the Wnt/Beta-Catenin Pathway to Regulate Bone Formation in the Adult Skeleton. Endocrinology, 148, 2635-2643. http://dx.doi.org/10.1210/en.2007-0270

[27] Garcia-Martin, A., Rozas-Moreno, P., Reyes-Garcia, R., Morales-Santana, S., Garcia-Fontana, B., Garcia-Salcedo, J.A. and Munoz-Torres, M. (2012) Circulating Levels of Sclerostin Are Increased in Patients with Type 2 Diabetes Mellitus. Journal of Clinical Endocrinology \& Metabolism, 97, 234-241. http://dx.doi.org/10.1210/jc.2011-2186

[28] Klangjareonchai, T. and Nimitphong, H. (2014) Circulating Sclerostin and Irisin Are Related and Interact with Gender to Influence Adiposity in Adults with Prediabetes. International Journal of Endocrinology, 2014, Article ID: 261545.

[29] Desjardin, C., Chat, S., Gilles, M., Legendre, R., Riviere, J., Mata, X., Balliau, T., Esquerre, D., Cribiu, E.P., Betch, 
J.M. and Schibler, L. (2014) Involvement of Mitochondrial Dysfunction and ER-Stress in the Physiopathology of Equine Osteochondritis Dissecans (OCD). Experimental and Molecular Pathology, 96, 328-338. http://dx.doi.org/10.1016/j.yexmp.2014.03.004

[30] Yoon, J.C., Ng, A., Kim, B.H., Bianco, A., Xavier, R.J. and Elledge, S.J. (2010) Wnt Signaling Regulates Mitochondrial Physiology and Insulin Sensitivity. Genes \& Development, 24, 1507-1518. http://dx.doi.org/10.1101/gad.1924910

[31] Robling, A.G., Niziolek, P.J., Baldridge, L.A., Condon, K.W., Allen, M.R., Alam, I., Mantila, S.M., Gluhak-Heinrich, J., Bellido, T.M., Harris, S.E. and Turner, C.H. (2008) Mechanical Stimulation of Bone in Vivo Reduces Osteocyte Expression of Sost/Sclerostin. The Journal of Biological Chemistry, 283, 5866-5875. http://dx.doi.org/10.1074/jbc.M705092200

[32] Reppe, S., Noer, A., Grimholt, R.M., Halldorsson, B.V., Medina-Gomez, C., Gautvik, V.T., Olstad, O.K., Berg, J.P., Datta, H., Estrada, K., Hofman, A., Uitterlinden, A.G., Rivadeneira, F., Lyle, R., Collas, P. and Gautvik, K.M. (2014) Methylation of Bone SOST, Its mRNA, and Serum Sclerostin Levels Correlate Strongly with Fracture Risk in Postmenopausal Women. Journal of Bone and Mineral Research, Published Online. http://dx.doi.org/10.1002/jbmr.2342

[33] Delgado-Calle, J., Arozamena, J., Perez-Lopez, J., Bolado-Carrancio, A., Sanudo, C., Agudo, G., de la Vega, R., Alonso, M.A., Rodriguez-Rey, J.C. and Riancho, J.A. (2013) Role of BMPs in the Regulation of Sclerostin as Revealed by an Epigenetic Modifier of Human Bone Cells. Molecular and Cellular Endocrinology, 369, 27-34. http://dx.doi.org/10.1016/j.mce.2013.02.002 
Scientific Research Publishing (SCIRP) is one of the largest Open Access journal publishers. It is currently publishing more than 200 open access, online, peer-reviewed journals covering a wide range of academic disciplines. SCIRP serves the worldwide academic communities and contributes to the progress and application of science with its publication.

Other selected journals from SCIRP are listed as below. Submit your manuscript to us via either submit@scirp.org or Online Submission Portal.
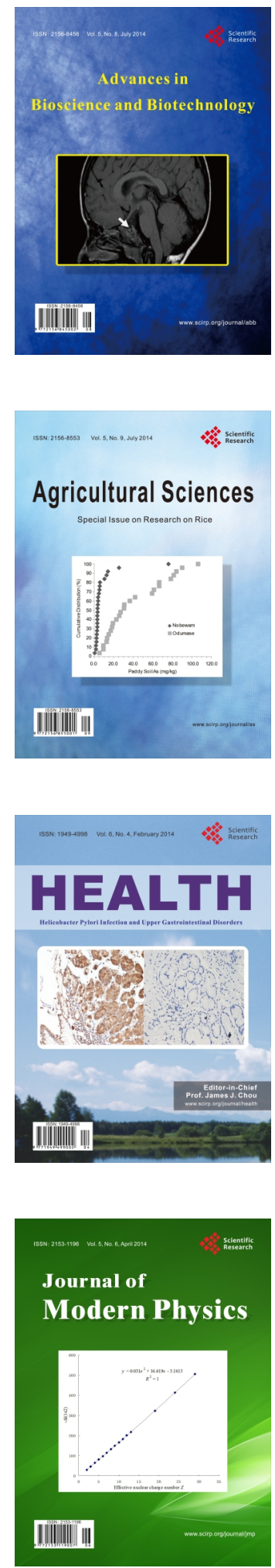
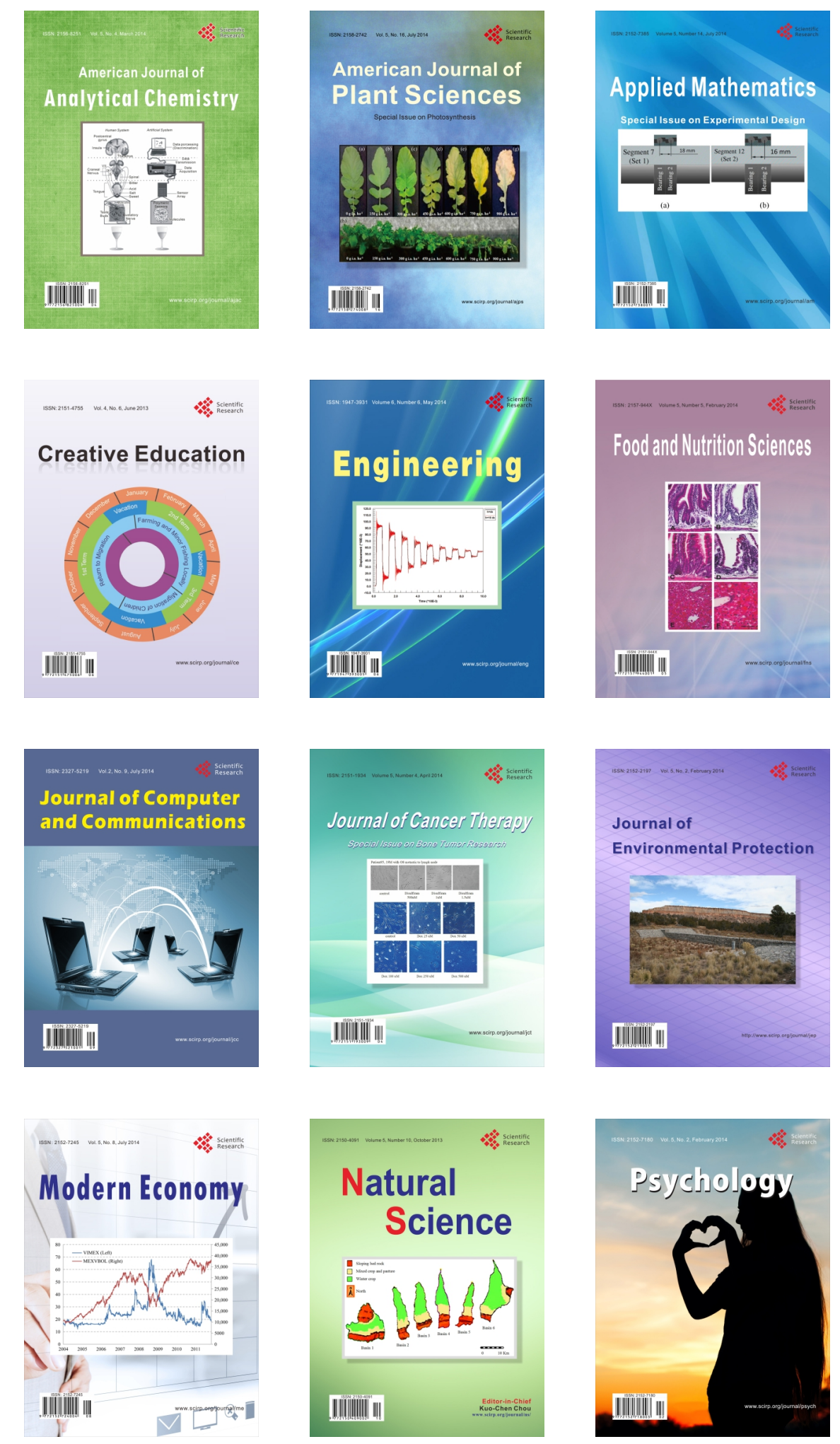